\title{
Relationship between the Structure and Taste of Some Naringin Analogs ${ }^{\dagger}$
}

\author{
Sachiko EsAKr, Fukuko KonisHI and Shintaro KamiYA \\ Food Chemistry Laboratory, Shizuoka Women's University, Yada 409, Japan
}

Received June 12, 1978

\begin{abstract}
The following three new analogs of naringin (I) were synthesized. Naringein-7-[6'-Omethyl-O- $\alpha$-L-mannopyranosyl-(1 $\rightarrow 2)-\beta$-D-glucopyranoside] (II), naringenin-7-[6'-O-methylO- $\alpha$-D-mannopyranosyl-( $1 \rightarrow 2)-\beta$-D-glucopyranoside $]$ (III) and naringenin-7-[O- $\alpha-\mathrm{L}-\mathrm{rhamno-}$ pyranosyl-(1 $\rightarrow 6)-\beta$-D-galactopyranoside] (XVI).

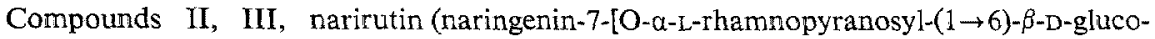
pyranoside] (XV) and XVI are $0.10,0.13,0.05$ and 0.08 times as bitter as I, respectively. From the above organoleptic result it was concluded that the methyl group of $L$-rhamnose in $I$ is one of the essential factors for intense bitterness. Attachment of $\alpha$-L-rhamnose to the 6"'-position of D-glucoside or D-galactoside of naringenin does not abolish the taste of the resulting glycosides but elicits a moderate bitter taste.
\end{abstract}

In our series of studies,,$^{(\sim 5)}$ we reported the syntheses and tastes of many isomers and analogs of naringin (I), naringenin-7-[O- $\alpha-\mathrm{L}$ rhamnopyranosyl-(l $\rightarrow 2)-\beta$-D-glucopyranoside], and discussed their structure-taste relationship. When $\alpha$-L-rhamnose in I is replaced by $\alpha$-Dglucose or $\alpha$-D-galactose, bitterness is retained to a considerable extent. But when it is replaced by $\alpha$-D- or $\alpha$-L-mannose, bitterness decreases extremely. The conformation of the $\mathrm{C}-1$ and $\mathrm{C}-2$ hydroxyl groups of $\alpha$-D-glucose and $\alpha$-D-galactose are gauche form while those of $\alpha$-D- and $\alpha-L$-mannose are trans form. Therefore, we hypothesized that the former conformation of the sugar structure was required to elicit bitterness while the latter was not. However, since $\alpha$-L-rhamnose in $I$ is also effective for intense bitterness in spite of its having antiglycol conformation at $\mathrm{C}-1$ and $\mathrm{C}-2$ hydroxyl groups, the non-polar nature of the methyl group at $\mathrm{C}-5$ is assumed to play an important role for bitterness. If this assumption is correct, methylation of the polar hydroxylmethyl group of both mannosyl residues to decrease polarity is thought to enhance the bitter taste of compounds XVIII and XIX (see below). From the above standpoint we

$\uparrow$ Synthesis of Flavonoid Glycosides. Part IX. For previous paper, see Agric. Biol. Chem,, 42, 941 (1978). synthesized naringenin-7-[6'-O-methyl-O- $\alpha-\mathrm{L}-$ mannopyranosyl-( $1 \rightarrow 2)-\beta$-D - glucopyranoside] (II) and naringenin-7-[6'-O-methyl-O- $\alpha$-D-mannopyranosyl- $(1 \rightarrow 2)-\beta$-D-glucopyranoside] (III) and examined their taste.

Tritylation followed by acetylation of syrupy L-mannose ${ }^{6)}$ gave crystalline 1,2,3,4-tetra-Oacetyl-6-O-trityl- $\beta$-L-mannopyranose (IV). IV was detritylated with hydrogen bromide to afford 1,2,3,4-tetra- $\mathrm{O}$-acetyl- $\beta$ - $\mathrm{L}$-mannopyranose (V) which was further methylated with diazomethane to 1,2,3,4-tetra-O-acetyl-6-Omethyl- $\beta$-L-mannopyranose (VI) by the method of Mastronardi et al. ${ }^{7,8}$ In a similar way 1,2,3,4-tetra-O-acetyl- 6-O-methyl- $\beta$-D-mannopyranose (VII) was prepared from D-mannose. On treatment with hydrogen bromide, VI and VII afforded 2,3,4-tri-O-acetyl-6-O-methyl- $\alpha$ L-mannopyranosyl bromide (VIII) and 2,3,4tri-O-acetyl-6-O-methyl- $\alpha$-D-mannopyranosyl bromide, respectively. Condensation of VIII and IX with 1,3,4,6-tetra-O-acetyl- $\alpha$-D-glucopyranose by the method of Helferich and Zirner $^{9)}$ resulted in the formation of $1,3,4,6$,$2^{\prime}, 3^{\prime}, 4^{\prime}$-hepta-O -acetyl- $6^{\prime}-\mathrm{O}$-methyl-2-O- $\alpha$-Lmannopyranosyl- $\alpha$-D-glucopyranose $(\mathrm{X})$ and $1,3,4,6,2^{\prime}, 3^{\prime}, 4^{\prime}$-hepta- O -acetyl-6'-O -methyl-2O- $\alpha$-D-mannopyranosyl- $\alpha$-D-glucopyranose(XI) respectively. $\mathrm{X}$ and $\mathrm{XI}$ were brominated with hydrogen bromide to give $3,4,6,2^{\prime}, 3^{\prime}, 4^{\prime}$-hexa- 


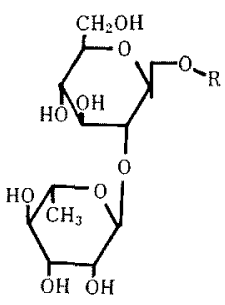

(I)

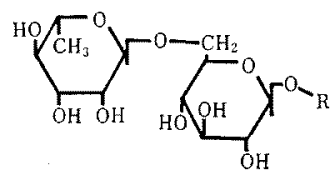

(XV)

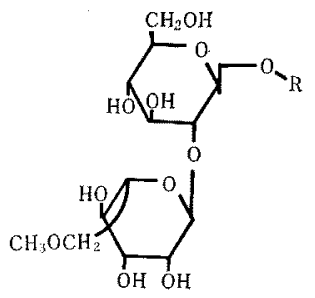

(II)

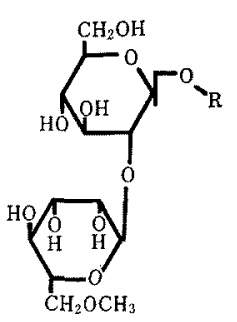

(III)

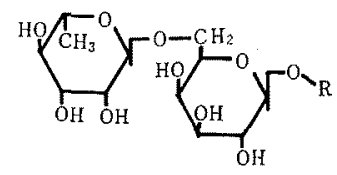

(XVI)

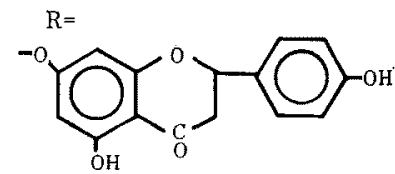

O-acetyl-6'-O-methyl-2-O- $\alpha$-L-mannopyranosyl $\alpha$-D-glucopyranosyl bromide (XII) and 3,4,6,$2^{\prime}, 3^{\prime}, 4^{\prime}$-hexa-O -acetyl- $6^{\prime}$ - O -methyl-2-O- $\alpha$-Dmannopyranosyl- $\alpha$-D-glucopyranosyl bromide (XIII), respectively. Coupling of naringenin (XIV) with each of XII and XIII followed by deacetylation with methanolic sodium methoxide yielded II and III.

Narirutin (XV), an isomer of naringin, was originally isolated by Gentili and Horowitz ${ }^{10}$ from navel and Valencia oranges and elucidated to have the structure of naringenin-7-[O- $\alpha-\mathrm{L}$ rhamnopyranosyl $(1 \rightarrow 6)-\beta$-D-glucopyranoside]. $\mathrm{XV}$ was reported to be entirely tasteless and, from the above findings, they concluded that the transposition of rhamnose to the 6-position of glucose resulted in complete disappearance of bitterness. Subsequently Wagner et al. ${ }^{11}$ reported the synthesis of XV and mentioned it to be also tasteless. On the other hand we $\mathrm{e}^{12 \sim_{14}}$ investigated the occurrence and distribution of $X V$ in many species of citrus plants and could isolate XV as colorless needles which has some bitterness in contrast to results of American and German workers. This discrepancy in the taste prompted us further to investigate the synthesis of naringenin-7-[O- $\alpha$-L-rhamnopyranosyl-( $1 \rightarrow 6)-\beta$-D-galactopyranoside] (XVI) and to examine its taste. Coupling of XIV with $2,3,4,2^{\prime}, 3^{\prime}, 4^{\prime}$-hexa- $\mathrm{O}$-acetyl-6-O - $\alpha$-L-rhamnopyranosyl - $\alpha-\mathrm{D}$ - galactopyranosyl bromide (XVII) followed by deacetylation yielded XVI.

The tastes of II, III, XV and XVI were examined in comparison with that of $I$ by the same method as described in previous papers. $^{1 \sim 5 \gamma}$ As the result, II, III, XV and XVI were found to be $0.10,0.13,0.05$ and 0.08 times as bitter as I on a weight basis. II and III or XV and XVI had almost the same degree of bitterness, respectively. As reported previously, ${ }^{{ }^{\prime}}$, we prepared naringenin-7-[O- $\alpha-\mathrm{L}$ mannopyranosyl-( $1 \rightarrow 2)-\beta$-D -glucopyranoside] (XVIII) and naringenin-7-[O- $\alpha-D-$ mannopyranosyl- $(1 \rightarrow 2)-\beta$-D-glucopyranoside] (XIX) and found them to be 0.04 and 0.01 times as bitter as I. From comparison of the tastes of II and XVIII or III and XIX, respectively, it may be said that methylation of the 6-hydroxyl group of $L$ - and D-mannose units in XVIII and XIX enhances bitterness and $I I$ and III have bitterness comparable to that of neohesperidin which has been reported ${ }^{(5)}$ to be about one-tenth as bitter as I. From the above fact one of the essential factors required for intense bitterness in the sugar component of $I$ is the methyl group of L-rhamnose as has already been emphasized by us. ${ }^{5}$ From the fact that $\mathrm{XV}$ and XVI are one-twentieth as bitter as I, migration of L-rhamnose unit to the 6-position of D-glucose in I and of D-galactose in naringenin-7-[O - $\alpha$ - L -rhamnopyranosyl- $(1 \rightarrow 2)-\beta$-Dgalactopyranoside $],{ }^{16)}$ which was reported to be as bitter as I, decreases bitterness considerably but does not abolish the taste entirely in contrast to the report of Horowitz and Gentili. ${ }^{15}$, 


\section{EXPERIMENTAL}

Mps, UV, IR and NMR spectra were obtained with the same equipments as described in the previous paper. ${ }^{1)}$ Thin-layer chromatographic analyses were carried out as follows using silica gel plates.

Solvent A. benzene-ethyl acetate $6: 1$

Solvent B. benzene-ethyl acetate $7: 3$

Solvent C. chloroform-acetone 9:1

Solvent $D$. benzene-acetone $9: 1$

Solvent E. ethyl acetate-methanol-water $80: 14: 10$

Two percent ferric chloride in ethanol or $5 \%$ sulfuric acid in ethanol was used as spray reagents. Silica gel plates sprayed with the latter reagent were heated at $100^{\circ} \mathrm{C}$ for ten minutes.

1) 1,2,3,4-Tetra-O-acetyl-6-O-trityl- $\beta$-L-mannopyranose $(I V)$. Well dried syrupy L-mannose $(54 \mathrm{~g})$ prepared according to the direction of Sowden and Fischer ${ }^{8)}$ and trityl chloride $(86 \mathrm{~g})$ were dissolved in anhydrous pyridine $(270 \mathrm{ml})$ at $40^{\circ} \mathrm{C}$ and kept for two days at the same temperature with stirring. Successively, acetic anhydride $(162 \mathrm{ml})$ was added without cooling in one portion into the reaction mixture which was kept for $24 \mathrm{hr}$ at room temperature. After removal of white precipitate (trityl carbinol) the flltrate was poured into ice-water with stirring. The resulting white syrup was dissolved in chloroform, washed with water repeatedly and dried over anhydrous sodium sulfate overnight. The filtrate, after the evaporation of the solvent, yielded a syrup which was crystallized from $95 \%$ ethanol to give IV as needles. Yield, $53 \mathrm{~g}(29.94 \%$.) mp $201 \sim 203^{\circ} \mathrm{C}$. TLC Rf 0.64 (solvent A). $[\alpha]_{\mathrm{D}}^{30}-5.5^{\circ}$ $\left(c=4.0, \mathrm{CHCl}_{3}\right)$. Anal. Found: $\mathrm{C}, 66.35 ; \mathrm{H}, 5.83$; Calcd. for $\mathrm{C}_{33 \mathrm{H}_{34}} \mathrm{O}_{10}: \mathrm{C}, 67.12 ; \mathrm{H}, 5.76 \%$. NMR $\delta \underset{\text { Mesisi }}{\mathrm{CDCl}}$ : actoxyl group: $1.71,1.98,2.02,2.22(12 \mathrm{H}$, each singlet); sugar protons: $3.10 \sim 3.77(3 \mathrm{H}), 4.87 \sim$ $5.53(3 \mathrm{H}), 5.78(\beta-1 \mathrm{H}$, doublet, $J=1 \mathrm{~Hz})$; trityl protons: $7.08 \sim 7.58(15 \mathrm{H})$.

2) 1,2,3,4-Tetra-O-acetyl- $\beta$-L-mannopyranose $(V)$. IV (27 g) was dissolved in glacial acetic acid $(117 \mathrm{ml})$ and the solution was cooled to $10^{\circ} \mathrm{C}$. Acetic acid $(11 \mathrm{ml})$ saturated with hydrogen bromide at $0^{\circ} \mathrm{C}$ was added and the solution was shaken for forty-five seconds. After removal of trityl bromide, the solution was poured into ice-water and the precipitate was treated in the usual way. The residual syrup was crystallized from ether to give $\mathrm{V}$ as colorless plates. Yield, $11.5 \mathrm{~g}$ (72.24\%). mp $135 \sim 136^{\circ} \mathrm{C}$. TLC $R f 0.17$ (solvent B). $[\alpha]_{\mathrm{D}}^{28}+19.25^{\circ}\left(c=4.0, \mathrm{CHCl}_{3}\right)$. Anal. Found: C, 47.94; $\mathrm{H}, 5.86$; Calcd. for $\mathrm{C}_{14} \mathrm{H}_{20} \mathrm{O}_{10}$ : C, 48.27; H, 5.75\%. NMR $\delta{ }_{\text {Mesii }}^{\mathrm{CDCl}}$ : acetoxyl group: $2.00 \sim 2.40(12 \mathrm{H}$, multiplet); sugar protons: $2.43 \sim 3.85(3 \mathrm{H}), 5.10 \sim 5.63(3 \mathrm{H})$, $5.83(\beta-1 \mathrm{H}$, doublet, $J=1 \mathrm{~Hz})$.

3) 1,2,3,4-Tetra-O-acetyl-6-O-methyl- $\beta$-L-manno- pyranose $(I V)$. To a solution of $\mathrm{V}(7.2 \mathrm{~g})$ in dichloromethane $(72 \mathrm{ml})$ boron trifluoride etherate $(0.4 \mathrm{ml})$ and an excess amount of diazomethane-chloroform solution was added at $0^{\circ} \mathrm{C}$. The reaction mixture was treated according to the direction of Deferrari et $a^{8}{ }^{8}$ and the final syrup was crystallized from ethanol to give VI as needles with a yield of $4.7 \mathrm{~g}(62.76 \%), \mathrm{mp} 105 \sim 106^{\circ} \mathrm{C}$ (EtOH). TLC Rf 0.39 (solvent B). $[\alpha]_{\mathrm{D}}^{25}+15.5^{\circ}(c=$ 2.0, $\mathrm{CHCl}_{3}$ ). Anal. Found: $\mathrm{C}, 49.68 ; \mathrm{H}, 6.25$; Calcd. for $\mathrm{C}_{15} \mathrm{H}_{22} \mathrm{O}_{10}: \mathrm{C}, 49.72 ; \mathrm{H}, 6.08 \%$ NMR $\delta_{\mathrm{Mes}}^{\mathrm{CDCl}}$ : acetoxyl group: $1.97 \sim 2.28(12 \mathrm{H}$, multiplet); methoxyl group: $3.32(3 \mathrm{H}$, singlet); sugar protons: $3.40 \sim 3.88$ $(3 \mathrm{H}), 5.07 \sim 5.48(3 \mathrm{H}), 5.78(\beta-1 \mathrm{H}$, doublet, $J=1 \mathrm{~Hz})$.

4) 1,2,3,4-Tetra-O-acetyl-6-O-methyl- $\beta$-D-mannopyranose $(V I I) . \quad 1,2,3,4-$ Tetra-O-acetyl- $\alpha$-D-mannopyranose $\left.^{17}\right)(5 \mathrm{~g})$ was methylated with diazomethane as described above and VII was obtained as needles with a yield of $3 \mathrm{~g}(57.69 \%), \mathrm{mp} 104 \sim 107^{\circ} \mathrm{C}$, (EtOH). TLC $R f 0.39$ (solvent B). $[\alpha]_{\mathrm{D}}^{25}-15.0^{\circ} \quad\left(c=2.0, \mathrm{CHCl}_{3}\right)$. Anal. Found: C, 49.67; $\mathrm{H}, 6.25$; Calcd. for $\mathrm{C}_{15} \mathrm{H}_{22} \mathrm{O}_{10}$ : $\mathrm{C}, 49.72 ; \mathrm{H}, 6.08 \%$. NMR $\delta_{\mathrm{Mes}}^{\mathrm{CDCl}_{1}}$ : acetoxyl group: $2.03,2.08,2.10,2.23(12 \mathrm{H}$, each singlet); methoxyl group: $3.36(3 \mathrm{H}$, singlet); sugar protons: $3.43 \sim 4.00$ $(3 \mathrm{H}), 5.1 \sim 5.53(3 \mathrm{H}), 5.83(\beta-1 \mathrm{H}$, doublet, $J=1 \mathrm{~Hz})$.

5) 2,3,4-Tri-O-acetyl-6-O-methyl- $\alpha-\mathrm{L}-$ mannopyranosyl bromide (VIII) and 2,3,4-tri-O-acetyl-6-O-methyl-a-Dmannopyranosyl bromide $(L X)$. Each of VI and VII ( $18 \mathrm{~g}$ and $11 \mathrm{~g}$ ) was dissolved in a minimum amount of chloroform and acetic acid $(72 \mathrm{ml}$ and $45 \mathrm{ml}$ ) saturated with hydrogen bromide at $0^{\circ} \mathrm{C}$ was added. The reaction mixture was kept at $0^{\circ} \mathrm{C}$ for $30 \mathrm{~min}$ and then worked up in the usual manner. ${ }^{13}$ Both VIII and IX were obtained as syrup $(18.5 \mathrm{~g}$ and $11.4 \mathrm{~g}$ ) with small amounts of impurities, which failed to crystallize. Since they were relatively unstable, they were used immediately for the next reaction. TLC 0.77 and 0.75 (solvent $\mathrm{C}$ ).

6) $1,3,4,6,2^{\prime}, 3^{\prime}, 4^{\prime}$-Hepta-O-acetyl-6'-O-methyl-2-O$\alpha$-L-mannopyranosyl- $\alpha$-D-glucopyranose $(X) . \quad 1,3,4,6-$ Tetra-O-acetyl- $\alpha$-D-glucopyranose $(15.8 \mathrm{~g})$ wat dissolved in a solution containing mercuric cyanide $(8.25 \mathrm{~g})$ and mercuric bromide $(12.5 \mathrm{~g})$ in acetonitrile $(165 \mathrm{ml})$ and the resultant solution was treated with VIII (18.5 g). After being kept for $24 \mathrm{hr}$ at room temperature, the reaction mixture was treated in the same way as described in a literature. ${ }^{9}>\mathrm{X}$ was obtained as amorphous powder, which failed to crystallize after all. Yield, $8.39 \mathrm{~g}(28.43 \%)$. TLC $R f 0.67$ (solvent B). $[\alpha]_{\mathrm{D}}^{10} 0^{\circ}$ ( $c=4.0, \mathrm{CHCl}_{3}$ ). Anal. Found: $\mathrm{C}, 49.83 ; \mathrm{H}, 5.86$; Calcd. for $\mathrm{C}_{27} \mathrm{H}_{38} \mathrm{O}_{18}: \mathrm{C}, 49.85 ; \mathrm{H}, 5.85 \%$. NMR $\delta \frac{\mathrm{CDCla}}{\mathrm{Mesil}}:$ acetoxyl group: $2.20 \sim 2.30(21 \mathrm{H}$, multiplet $)$; methoxyl group: $3.36(3 \mathrm{H}$, singlet); sugar protons: $3.40 \sim 4.30(9 \mathrm{H}), 4.90 \sim 5.30(6 \mathrm{H}), 5.46\left(\alpha-1^{\prime} \mathrm{H}\right.$, doublet $J=2 \mathrm{~Hz}), 6.28(a-1 \mathrm{H}$, doublet, $J=3 \mathrm{~Hz})$. 
Deacetylation of $\mathrm{X}$ with sodium methoxide gave the free disaccharide $\left(\mathrm{X}^{\prime}\right) . \quad[\alpha]_{\mathrm{D}}^{20}+15^{\circ} \quad(c=2,0, \mathrm{MeOH})$. TLC $R f 0.28$ (BuOH-AcOH- $\mathrm{H}_{2} \mathrm{O} 4: 1: 2$ ).

7) $1,3,4,6,2^{\prime}, 3^{\prime}, 4^{\prime}$-Hepta-O-acetvl-6'-O-methyl-2-O$\alpha$-D-mannopyranosyl- $\alpha$-D-glucopyranose (XI). Condensation of 1,3,4,6-tetra-O-acetyl- $\alpha$-D-glucopyranose ${ }^{\text {B) }}$ $(9.6 \mathrm{~g})$ with IX $(11.4 \mathrm{~g})$ in the presence of mercuric cyanide $(5 \mathrm{~g})$ and mercuric bromide $(7.6 \mathrm{~g})$ in acetonitrile $(100 \mathrm{ml})$ in a way similar to that described above gave $\mathrm{XI}$ as amorphous powder with a yield of $5.5 \mathrm{~g}$ $(30.67 \%) . \quad$ TLC $R f 0.67$ (solvent B). $\quad[\alpha]_{\mathrm{D}}^{10}+98.8^{\circ}(c=$ 4.0, $\mathrm{CHCl}_{3}$ ). Anal. Found: C, 49.79; H, 5.83; Caled. for $\mathrm{C}_{27} \mathrm{H}_{38} \mathrm{O}_{18}: \mathrm{C}, 49.85 ; \mathrm{H}, 5.85 \%$. NMR $\delta_{\text {Mesi }}^{\mathrm{CDCl}}$ : acetoxyl group: $1.93(3 \mathrm{H}$, singlet), $1.97(3 \mathrm{H}$, singlet), 2.0 (3H, singlet), 2.03 (6H, singlet), 2.06 (3H, singlet), 2.17 (3H, singlet), methoxyl group: 3.30 (3H, singlet); sugar protons: $3.37 \sim 4.23(9 \mathrm{H}), 4.80 \sim 5.53(7 \mathrm{H}), 6.30$ $(\alpha-1 \mathrm{H}$, doublet, $J=3 \mathrm{~Hz}$ ).

8) $\quad 3,4,6,2^{\prime}, 3^{\prime}, 4^{\prime}$-Hexa-O-acetyl-6'-O-methyl-2-O$\alpha$-L-mannopyranosyl- $\alpha$-D-glucopyranosyl bromide $(X I I)$

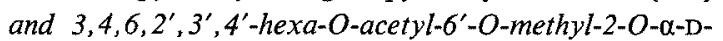
mannopyranosyl- $\alpha$-D-glucopyranosyl bromide (XIII). Each of X $(8 \mathrm{~g})$ and XI $(11 \mathrm{~g})$ was reacted with acetic acid $(132 \mathrm{ml}$ and $45 \mathrm{ml})$ saturated with hydrogen bromide for $50 \mathrm{~min}$ at $0^{\circ} \mathrm{C}$ and then treated in the usual manner as described above to afford XII (12 g) and XIII $(6 \mathrm{~g})$, respectively, with small amounts of impurities. Being relatively unstable, they were used immediately in the following step. TLC XII, $R f 0.22$; XIII, $R f 0.22$ (solvent D).

9) $\quad 2,3,4,2^{\prime}, 3^{\prime}, 4^{\prime}$-Hexa-O-acet yl-6-O- $\alpha$-L-rhamnopyranosyl- $\alpha$-D-galactopyranosyl bromide ( $\alpha$-acetobromorobinobiose) $(X V I I)$. Amorphous hepta-O-acetylrobinobiose $^{18)}(4.2 \mathrm{~g})$ was dissolved in chloroform $(5 \mathrm{ml})$ and acetic acid ( $22 \mathrm{ml}$ ) saturated with hydrogen bromide was added. After being allowed to stand for $2 \mathrm{hr}$, the solution was worked up as described above and somewhat impure XVII $(3.5 \mathrm{~g})$ used without purification in the next step. TLC $R f 0.33$ (solvent B).

10) Naringenin-7-[6'-O-methyl-O- $\alpha-\mathrm{L}-$ mannopyranosyl-( $(1 \rightarrow 2)-\beta$-D-glucopyranoside] (II). According to the previous paper, ${ }^{1)}$ naringenin $(5 \mathrm{~g})$ was coupled with $\mathrm{XII}(12 \mathrm{~g})$ in the presence of freshly prepared silver carbonate $(7 \mathrm{~g})$ and Drierite $(2 \mathrm{~g})$ in anhydrous quinoline $(80 \mathrm{ml})$. The condensation product, after deacetylation with $0.4 \%$ methanolic sodium methoxide, was purified on silica gel and polyamide columns. II was obtained as plates, $\mathrm{mp} 168 \sim 172^{\circ} \mathrm{C}$, with a yield of $0.66 \mathrm{~g}(5.64 \%)$. TLC $R f 0.45$ (solvent E). $[\alpha]_{\mathrm{D}}^{22}$ $-75.0^{\circ}\left(c=4.0, \mathrm{C}_{5} \mathrm{H}_{5} \mathrm{~N}\right)$. Anal. Found; $\mathrm{C}, 52.74 ; \mathrm{H}$, 5.86; Calcd. for $\mathrm{C}_{28} \mathrm{H}_{34} \mathrm{O}_{13} \cdot 11 / 2 \mathrm{H}_{2} \mathrm{O}: \mathrm{C}, 52.74 ; \mathrm{H}$, $5.80 \%$. UV $\lambda_{\max }^{\mathrm{MeOH}} \mathrm{nm}(\varepsilon): 282(17,729), 326(2,773)$; $\lambda_{\max }^{\mathrm{MeOH}-\mathrm{MeONa}} \mathrm{nm}(\varepsilon): \quad 284 \quad(13,815), \quad 432 \quad(18,258)$; $\lambda_{\max }^{\mathrm{MeOH}-\mathrm{AlCl}_{3}} \mathrm{~nm}(\varepsilon): 309(21,855), 384(3,591) ; \lambda_{\mathrm{max}}^{\mathrm{MeOH}}$ $\mathrm{AlCl}_{3}-\mathrm{HCl} \mathrm{nm}(\varepsilon): 307(19,342), 382(29,364) ; \lambda_{\max }^{\mathrm{MeOH}}$ Ac ONa $\mathrm{nm}(\varepsilon)$ : $284(21,192), 300(7,867) . \quad$ IR cm$~^{-1}: 3350$ $(\mathrm{OH}), 1610(\mathrm{C}=\mathrm{O})$.

Acetylation of II with a mixture of acetic anhydride and pyridine in the usual manner gave heptaacetate (II'), mp $123 \sim 125^{\circ} \mathrm{C}$. Anal. Found: C, 54.75; H, 5.28; $[\alpha]_{D}^{22}-44.0^{\circ}\left(c=2.0, C_{5} \mathrm{H}_{5} \mathrm{~N}\right)$. Calcd. for $\mathrm{C}_{44} \mathrm{H}_{80} \mathrm{O}_{23}$ : $\cdot \mathrm{H}_{2} \mathrm{O}: \mathrm{C}, 54.77 ; \mathrm{H}, 5.39 \%$. NMR $\delta_{\text {Mesila }}^{\mathrm{CDCl}}$ : acetoxyl protons; $1.90 \sim 2.20(18 \mathrm{H}$, multiplet, sugar acetoxyl protons), $2.30,2.36(6 \mathrm{H}$, each singlet, aromatic acetoxyl protons); methoxyl protons: $3.35(3 \mathrm{H}$, singlet); sugar protons: $3.30 \sim 4.25(7 \mathrm{H}$, multiplet), $4.85 \sim 5.40(7 \mathrm{H}$, multiplet); aglycon: H-3: $2.70 \sim 3.13(2 \mathrm{H}$, multiplet); H-2: $5.40 \sim 5.60$ (multiplet); H-6: 6.40 (doublet, $J=$ $2 \mathrm{~Hz}$ ); H-8: 6.55 (doublet, $J=2 \mathrm{~Hz}$ ); $\mathrm{H}_{-1}{ }^{\prime}, \mathrm{H}-5^{\prime}$ : $7.06(2 \mathrm{H}$, doublet, $J=8 \mathrm{~Hz}) ; \mathrm{H}-2^{\prime}, \mathrm{H}-6^{\prime}: 7.40(2 \mathrm{H}$, doublet, $J=8 \mathrm{~Hz}$ ).

11) Naringenin-7-[6'-O-methyl-O- $\alpha-\mathrm{D}-$ mannopyranosyl-( $(I \rightarrow 2)-\beta-\mathrm{D}-$ glucopyranoside] (III). Coupling of naringenin $(2.5 \mathrm{~g})$ with XIII $(6 \mathrm{~g})$ in the same manner as described above yielded III as needles, $\mathrm{mp} 235$ $237^{\circ} \mathrm{C}$. Yield, $0.69 \mathrm{~g}(5.90 \%$ ). TLC Rf 0.48 (solvent E). $[\alpha]_{D}^{20}+8.75^{\circ}\left(c=4.0, \mathrm{C}_{5} \mathrm{H}_{5} \mathrm{~N}\right)$. Anal. Found: $\mathrm{C}$, 52.45; $\mathrm{H}, 5.80$; Calcd. for $\mathrm{C}_{28} \mathrm{H}_{34} \mathrm{O}_{15} \cdot 11 / 2 \mathrm{H}_{2} \mathrm{O}: \mathrm{C}$, $52.74 ; \mathrm{H}, 5.80 \%$. IR $\nu \mathrm{cm}^{-1}: 3400(\mathrm{OH}), 1610(\mathrm{C}=0)$. UV $\lambda_{\max }^{\mathrm{MeOH}} \mathrm{nm}(\varepsilon): 284(18,782), 333(4,324) ; \lambda_{\max }^{\mathrm{MeOH}}-$ $\mathrm{MeONa} \mathrm{nm}(\varepsilon): 284(13,073), 410(23,321) ; \lambda_{\max }^{\mathrm{MeOH}-\mathrm{AlOl}}$ $\mathrm{nm}(\varepsilon): 307(22,206), 393(5,470) ; \lambda_{\mathrm{max}}^{\mathrm{MeOH}-\mathrm{AlCl}_{3}-\mathrm{HCl}} \mathrm{nm}(\varepsilon)$ : $306(19,927), 388(5,270) ; \lambda_{\max }^{\mathrm{M} \odot \mathrm{OH}-\mathrm{AcONa}} \mathrm{nm}(\varepsilon): 282$ $(22,206), 330(6,028)$. Acetate, $\mathrm{mp} 118 \sim 121^{\circ} \mathrm{C}$. $[\alpha]_{D}^{22}$ $+15.0^{\circ}\left(c=2.0, \mathrm{C}_{5} \mathrm{H}_{5} \mathrm{~N}\right)$. Anal. Found: C, 54.81; $\mathrm{H}, 5.25$; Calcd. for $\mathrm{C}_{44} \mathrm{H}_{50} \mathrm{O}_{23} \cdot \mathrm{H}_{2} \mathrm{O}: \mathrm{C}, 54.77 ; \mathrm{H}, 5.39 \%$. NMR $\delta{\underset{M e}{4} \mathrm{Si}}^{\mathrm{CDCl}_{3}}$ : acetoxyl protons: $1.80 \sim 2.20(18 \mathrm{H}$, multiplet, sugar acetoxyl protons); $2.30,2.36(6 \mathrm{H}$, each singlet, aromatic acetoxyl protons); methoxyl protons: $3.33(3 \mathrm{H}$, singlet); sugar protons: $3.36 \sim 4.26(7 \mathrm{H}$, multiplet), $4.90 \sim 5.36$ (7H, multiplet); aglycon: $\mathrm{H}-3$ : $2.70 \sim 3.03$ ( $2 \mathrm{H}$, multiplet); $\mathrm{H}-2: 5.36 \sim 5.60$ (multiplet); $\mathrm{H}-6: 6.35$ (doublet, $J=2 \mathrm{~Hz}$ ); $\mathrm{H}-8: 6.53$ (doublet, $J=2 \mathrm{~Hz}$ ); H-3', H-5': $7.05(2 \mathrm{H}$, doublet, $J=8 \mathrm{~Hz})$; H-2', H-6': 7.4 (2H, doublet, $J=8 \mathrm{~Hz}$ ).

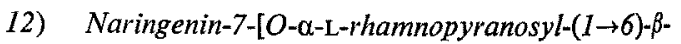
D-galactopyranoside $](X V I)$. Naringenin $(1.4 \mathrm{~g})$ was coupled with XVII ( $3.5 \mathrm{~g})$ in the same manner as described above and XVI was obtained as needles in a yield of $0.63 \mathrm{~g}(19.32 \%), \mathrm{mp} 173 \sim 176^{\circ} \mathrm{C} . \quad[\alpha]_{\mathrm{D}}^{20}-82.5^{\circ}$ $\left(c=2.4, \mathrm{C}_{5} \mathrm{H}_{5} \mathrm{~N}\right.$ ). TLC $R f 0.84$ (solvent E). Anal. Found: $\mathrm{C}, 51.86 ; \mathrm{H}, 6.00$; Calcd. for $\mathrm{C}_{27} \mathrm{H}_{32} \mathrm{O}_{14} \cdot 3 \mathrm{H}_{2} \mathrm{O}$ : C, $51.10 ; \mathrm{H}, 6.00 \%$. UV $\lambda_{\max }^{\mathrm{MeOH}} \mathrm{nm}(\varepsilon): 285(18,229)$, $330(3,674) ; \lambda_{\max }^{\mathrm{MeOH}}-\mathrm{MeONa} n m(\varepsilon): 286(14,556), 430$ $(14,959) ; \lambda_{\max }^{\mathrm{MeOH}-\mathrm{AlCl}_{3}} \mathrm{~nm}(\varepsilon): 308$ (22,635); 390(4,197); 
$\lambda_{\max }^{\mathrm{MeOH}-\mathrm{AlCl}_{3}-\mathrm{HCl}} \mathrm{nm}(\varepsilon): 304(20,559) ; \lambda_{\max }^{\mathrm{M} \theta \mathrm{OH}-\mathrm{AcONa}} \mathrm{nm}$ (c): $282(20,559), 338(5,309)$. IR $\nu \mathrm{cm}^{-1}: 3400$ $(\mathrm{OH}), 1620(\mathrm{C}=\mathrm{O})$. Acetate, mp $139 \sim 142^{\circ} \mathrm{C} .[\alpha]_{\mathrm{D}}^{25}$ $-30.7^{\circ} \quad\left(c=0.52, \mathrm{CHCl}_{3}\right)$. Anal. Found: $\mathrm{C}, 55.37$; $\mathrm{H}, 5.21$ : Calcd. for $\mathrm{C}_{43} \mathrm{H}_{48} \mathrm{O}_{22} \cdot \mathrm{H}_{2} \mathrm{O}: \mathrm{C}, 55.24 ; \mathrm{H}, 5.35 \%$. NMR $\delta{ }_{\mathrm{Me}_{4} \mathrm{Si}}^{\mathrm{CDCl}_{3}}:$ acetoxyl protons: $1.96(3 \mathrm{H}), 2.0(3 \mathrm{H})$, $2.03(6 \mathrm{H}), 2.10(3 \mathrm{H}), 2.20(3 \mathrm{H})(18 \mathrm{H}$, each singlet, sugar acetoxyl protons), $2.30,2.40(6 \mathrm{H}$, each singlet, aromatic acetoxyl protons); sugar protons: $1.19(3 \mathrm{H}$, doublet, $J=6 \mathrm{~Hz}$, methyl protons), $3.43 \sim 4.10$ ( $4 \mathrm{H}$, broad), $4.60 \sim 5.55$ ( $8 \mathrm{H}$, multiplet); aglycon: $\mathrm{H}-3: 2.76 \sim 3.06$ (2H, multiplet); H-2; $5.55 \sim 5.60$ (multiplet); H-6: 6.30 (doublet, $J=2 \mathrm{~Hz}$ ) ; H-8: 6.50 (doublet, $J=2 \mathrm{~Hz}$ ); H-3', H-5': $7.10(2 \mathrm{H}$, doublet, $J=8 \mathrm{~Hz}) ; \mathrm{H}-2^{\prime}, \mathrm{H}-6^{\prime}$ : $7.43(2 \mathrm{H}$, doublet, $J=8 \mathrm{~Hz})$.

\section{REFERENCES}

1) S. Kamiya, F. Konishi and S. Esaki, Agric. Biol. Chem., 38, 1785 (1974).

2) S. Kamiya, F. Konishi and S. Esaki, ibid, , 39, 733 (1975).

3) S. Kamiya, S. Esaki and F. Konishi, ibid., 39, 1757 (1975).

4) S. Kamiya, F. Konishi and S. Esaki, ibid., 40, 1887 (1976).

5) S. Esaki, S. Kamiya and F. Konishi, ibid., 41, 1791
(1977).

6) J. C. Sowden and H. O. L. Fischer, J.Am. Chem. Soc., 69, 1963 (1947); J. C. Sowden, J. Biol. Chem., 180, 55 (1959).

7) I. O. Mastronardi, S. M. Flematti, J. O. Deferrari and E. G. Gros, Carbohydr. Res., 3, 177 (1966).

8) J. O. Deferrari, E. G. Gros and O. Mastronardi, ibid., 4, 432 (1967).

9) B. Helferich and J. Zirner, Chem. Ber., 95, 2640 (1962).

10) B. Gentili and R. M. Horowitz, Bull. National Inst. Sci. India, 31, 78 (1969).

11) H. Wagner, G. Aurnhammer, L. Hörhammer and L. Farkas, Chem. Ber., 102, 2089 (1969).

12) M. Nishiura, S. Esaki and S. Kamiya, Agric. Biol. Chem., 33, 1109 (1969).

13) M. Nishiura, S. Kamiya, S. Esaki and F. Ito, ibid., 35, 1683 (1971).

14) M. Nishiura, S. Kamiya and S. Esaki, ibid, 35, 1691 (1971).

15) R. M. Horowitz and B. Gentili, J. Agric. Food Chem., 17, 696 (1969).

16) D. M. Van Niekerk and B. H. Koeppen, $E x$ perientia, 28, 123 (1972).

17) D. D. Reynolds and W. L. Evans, J. Am. Chem. Soc., 62, 66 (1940).

18) S. Kamiya, S. Esaki and M. Hama, Agric. Biol. Chem., 31, 261 (1967). 